\title{
A large volume spacer significantly reduces the effect of inhaled steroids on bone formation
}

\author{
Karim Meeran, Jacky M Burrin, Kate A Noonan, Christopher P Price, Philip W Ind
}

\begin{abstract}
Summary
Inhaled steroids are increasingly advocated as first line treatment for mild asthma. Some studies suggest that inhaled steroids suppress bone formation as reflected by a fall in plasma osteocalcin. Spacers have been shown to increase the proportion of inhaled aerosol that is deposited in the lungs and to reduce the amount swallowed.

We measured plasma osteocalcin levels to determine the effect on bone formation of inhaled beclomethasone dipropionate (BDP) with and without a $750 \mathrm{ml}$ spacer in a double-blind, randomised, placebocontrolled, cross-over study. Twenty-six healthy male volunteers took BDP $500 \mu \mathrm{g}$ (two puffs of Becloforte) together with two puffs of placebo, inhaled twice daily for seven days. One inhaler was taken directly while the other was inhaled through a $750 \mathrm{ml}$ spacer. After a two week washout period, the inhalers were exchanged so that BDP was taken by the alternate route for a further seven days. Fasting plasma osteocalcin levels were measured at $09.00 \mathrm{~h}$ before and at the end of each week.
\end{abstract}

After a week of BDP taken directly (without a spacer), osteocalcin levels fell from 11.8 (SEM 0.6) $\mathrm{ng} / \mathrm{ml}$ to 9.5 (SEM 0.5) $\mathrm{ng} / \mathrm{ml}(\mathrm{p}<0.001)$. After a week of BDP taken through a spacer, osteocalcin levels fell from 12.1 (SEM 0.5$) \mathrm{ng} / \mathrm{ml}$ to 11.1 (SEM 0.5) $\mathrm{ng} / \mathrm{ml}(\mathrm{p}<0.001)$. The fall in osteocalcin when a spacer was used was significantly less than when BDP was taken directly $(p<0.005)$. This is likely to be because the systemic effects on bone are caused by swallowed rather than inhaled BDP, and this is limited by the use of a spacer. Spacers should be more widely prescribed with inhaled steroids. Further prospective studies are indicated to evaluate whether spacers protect bone mass.

\section{Keywords: spacers, steroids, bone}

Clinical Biochemistry,

The London Hospital

Medical College,

Turner Street, London

E1 2AD, UK

J Burrin

KA Noonan

CP Price

Accepted 21 October 1994 phylaxis and treatment of asthma but their systemic use is severely limited by side effects. They are well known to cause progressive bone loss ${ }^{1}$ and have been associated with symptomatic osteoporosis. ${ }^{2}$ The use of inhaled rather than systemic steroids limits these and other side effects. Compared with oral steroids, they have been perceived as risk free but as the number of prescriptions for inhaled steroids has risen, so has the incidence of reported side effects. $^{3}$

Inhaled steroids are now advocated for the primary treatment of mild asthma. ${ }^{4-6}$ This means that many patients will be exposed to inhaled steroid therapy for prolonged periods. It is thus important that systemic steroid absorption from inhalers is minimised.

Spacers have been widely advocated for use by the elderly and by very young patients who may have difficulty co-ordinating their breathing with actuation of a metered dose inhaler. Recently, spacers have been advocated more widely. ${ }^{7}$ Compared with the use of a metered dose inhaler alone, spacers increase the proportion of the dose delivered to the airways while reducing the proportion swallowed, and may thereby reduce the total systemic exposure to steroid. ${ }^{8}$

Osteocalcin is a 49 amino acid vitamin-Kdependent peptide produced exclusively by osteoblasts. ${ }^{9}$ It is degraded in the kidney with a very short plasma half-life, ${ }^{10}$ and its plasma concentration is thus a good marker of osteoblast activity. We have previously shown that a standard dose of beclomethasone dipropionate (BDP) $(500 \mu \mathrm{g}$ bid) significantly and rapidly suppresses osteocalcin. ${ }^{11}$ Osteocalcin has been shown to be suppressed by doses as low as $400 \mu \mathrm{g}$ BDP daily and the degree of suppression seems to be dose dependent. ${ }^{12}$ Total alkaline phosphatase is a less specific marker of bone formation, as a significant proportion of serum alkaline phosphatase comes from liver. Bone-specific alkaline phosphatase should be more specific. The extent to which osteocalcin and alkaline phosphatase levels may be suppressed by steroids is controversial. ${ }^{11,13,14}$

The aim of the present study was to assess the effects of a spacer on BDP-induced suppression of osteocalcin and bone-specific alkaline phosphatase, in order to discover whether a spacer might limit systemic exposure to inhaled steroids.

\section{Subjects and methods}

Thirty healthy volunteers were recruited from male members of medical staff. Morning blood 
samples were taken to measure fasting plasma osteocalcin, total serum alkaline phosphatase and bone-specific alkaline phosphatase both before and at the end of two seven-day treatment periods. For each treatment period, volunteers were asked to inhale two puffs twice daily from each of two inhalers. The first was always taken through a large volume spacer (Volumatic) while the second was always taken directly. One contained placebo while the other contained active BDP in random order. The key was held by the hospital pharmacy. The inhalers were swapped over for the second treatment period. At least two weeks elapsed between the end of the first treatment period and the start of the second. All volunteers were instructed in inhaler technique both with and without a spacer. Written informed consent was obtained for each subject and the study was approved by the Hammersmith Hospital Ethics Committee.

Compliance was checked by weighing the inhalers at the beginning and end of each treatment period. All volunteers were given a diary card to fill in.

Four volunteers were excluded because of non-compliance: all had taken less than $60 \%$ of the stated dose, and in one case there was no change in the weight of the inhalers over the entire study! In the remaining 26 volunteers (mean age 30 years; SD 4.8), there was a good correlation between diary cards and the number of actuations of inhaler used. Each puff of the active inhaler contained $250 \mu \mathrm{g}$ of BDP. Volunteers were therefore taking $500 \mu \mathrm{g}$ twice daily, a standard prophylactic dose for asthma, either directly or via a spacer. The placebo inhaler taken by the alternative route contained propellant only and was supplied by Allen \& Hanbury's for demonstration purposes.

\section{ASSAYS}

All blood samples were collected into heparin and trasylol. Plasma was separated, frozen on dry ice immediately after collection, and stored at $-20^{\circ} \mathrm{C}$ for no longer than three months. All samples were given random numbers and assays were carried out blind. Plasma osteocalcin was measured using a second antibody radioimmunoassay (CIS (UK) Ltd, High Wycombe, Bucks) with a between-batch coefficient of variation of $5.4 \%$ and $6.8 \%$ at 3.8 and $15.9 \mathrm{ng} / \mathrm{ml}$, respectively. Bone-specific alkaline phosphatase was measured using an immunoradiometric assay (Tandem ${ }^{R}$ -
Ostase $^{\mathrm{TM}}$, Hybritech Inc, San Diego, CA 92126, USA) which utilises monoclonal antibodies which react preferentially with bone-specific alkaline phosphatase. ${ }^{15}$ The between-batch coefficient of variation was $9.8 \%$ at $21.9 \mathrm{ng} / \mathrm{ml}$. The reference range for bone-specific alkaline phosphatases in normal males is $7.0-28.0 \mathrm{ng} / \mathrm{ml}$.

Serum samples were analysed for calcium, albumin, creatinine and total alkaline phosphatase using routine Technicon SMAC methods.

\section{STATISTICS}

Changes in all levels with and without a spacer were compared using Student's paired $t$-test. ANOVA was used to compare changes between the groups.

\section{Results}

There were no side effects from either of the inhalers. Baseline plasma osteocalcin before each treatment period did not differ significantly, confirming that a two-week washout period was adequate. After a week of BDP taken directly (without a spacer), osteocalcin concentrations fell from 11.8 (SEM $0.6) \mathrm{ng} / \mathrm{ml}$ to 9.5 (SEM 0.5) $\mathrm{ng} / \mathrm{ml}(\mathrm{p}<0.001)$. After a week of BDP taken through a spacer, osteocalcin concentrations fell from 12.1 (SEM $0.5) \mathrm{ng} / \mathrm{ml}$ to 11.1 (SEM 0.5) $\mathrm{ng} / \mathrm{ml}$ $(\mathrm{p}<0.001)$. The fall in osteocalcin when a spacer was used was significantly less than when BDP was taken directly $(p<0.005)$. There was no significant change in creatinine, calcium, bone specific, or total alkaline phosphatase, with either inhaler, used either directly or via a spacer (see table).

\section{Discussion}

We have found plasma osteocalcin suppression to be an extremely sensitive marker of acute or short term systemic exposure to corticosteroids. Plasma osteocalcin concentrations are reliably suppressed by doses of inhaled steroids that are commonly used to treat asthma. The test is sensitive enough to distinguish between systemic exposure with and without a spacer. Osteocalcin concentrations return to baseline within two weeks of the inhaled steroid being discontinued.

Previous attempts to assess systemic steroid exposure have used the status of the hypo-

Table The effect of inhaled beclomethasone either taken directly or via a spacer. SEMs in parentheses. Beclomethasone-induced suppression of osteocalcin is significantly reduced (from 2.25 to $1.01 ; \mathrm{p}<0.005$ ) when a spacer is used

\begin{tabular}{|c|c|c|c|c|c|c|}
\hline \multirow[t]{2}{*}{ Test } & \multicolumn{3}{|l|}{ Direct } & \multicolumn{3}{|l|}{ Via spacer } \\
\hline & pre & post & $\begin{array}{l}\text { paired } \\
\text { difference }\end{array}$ & pre & post & $\begin{array}{l}\text { paired } \\
\text { difference }\end{array}$ \\
\hline Alkaline phosphatase (IU/l) & $85.2(9.4)$ & $84.9(9.2)$ & NS & $85.4(8.8)$ & $83.6(8.6)$ & NS \\
\hline BSAP (ng/ml) & $12.92(1.08)$ & $13.10(1.04)$ & NS & $13.86(1.28)$ & $13.76(1.26)$ & NS \\
\hline Calcium (mmol/l) & $2.34(0.02)$ & $2.37(0.02)$ & NS & $2.35(0.02)$ & $2.35(0.02)$ & NS \\
\hline Creatinine $(\mu \mathrm{mol} / \mathrm{l})$ & $99.1(1.96)$ & $96.2(1.74)$ & NS & $97.9(1.79)$ & $97.8(2.22)$ & NS \\
\hline Osteocalcin (ng/ml) & $11.77(0.56)$ & $9.52(0.52)$ & $2.25(0.317)$ & $12.06(0.52)$ & $11.05(0.52)$ & $1.01(0.151)$ \\
\hline
\end{tabular}

NS: not significant, BSAP: bone-specific alkaline phosphatase. 
thalamic-pituitary-adrenal (HPA) axis. This is difficult to assess reliably after steroid exposure. Acute steroid exposure rapidly suppresses both adrenocorticotropic hormone (ACTH) and cortisol. ${ }^{16}$ Small doses of systemic corticosteroid, such as that inadvertantly absorbed from a metered dose inhaler for asthma prophylaxis, have been thought to have a negligible effect on the HPA axis however. Doses larger than those used routinely have thus been used to study the effects of spacers. Farrer et al used a single large dose (2 mg BDP) and reported that $09.00 \mathrm{~h}$ cortisol suppression was less marked when a spacer was used. ${ }^{17}$ Such a study has not been possible with more usual doses of inhaled steroid because the large variability of all measures of the HPA axis, including stimulation tests, urinary and serum cortisol, ${ }^{18}$ and $\mathrm{ACTH}{ }^{19}$, makes small changes difficult to detect.

Teelucksingh et al found that osteocalcin suppression was more sensitive to acute steroid exposure than any test of the HPA axis. They showed that the metyrapone test was the most sensitive measure of HPA axis suppression following acute steroid exposure ${ }^{20}$ and that $800 \mu \mathrm{g}$ daily of inhaled BDP could be detected using this relatively invasive test. They also found that osteocalcin levels were suppressed by half this dose. ${ }^{12}$

Neither total nor bone-specific alkaline phosphatase were suppressed after a week of inhaled BDP by either route. The plasma half-life of alkaline phosphatase is between two and three days ${ }^{21}$ whereas that of osteocalcin is a number of hours. ${ }^{10}$ This might explain why we found a significant fall in osteocalcin without a change in bone-specific alkaline phosphatase. Nielsen et $\mathrm{al}^{13}$ gave $40 \mathrm{mg}$ prednisolone daily to volunteers for five days and found a $75 \%$ fall in osteocalcin but only a $6 \%$ fall in alkaline phosphatase.

It should be remembered that the clinical significance of changes in osteocalcin in patients taking oral or inhaled steroids is still uncertain. Osteocalcin is only a marker of bone formation and the development of osteoporosis is a balance between bone formation and bone resorption. Markers of bone resorption were not measured in this study. Some studies ${ }^{14}$ have found evidence of increased bone resorption as suggested by increased urinary hydroxyproline:creatinine ratios while others have found no change. ${ }^{13}$ As no studies have shown a

1 Reid IR. Pathogenesis and treatment of steroid osteoporosis Clin Endocrinol 1989; 30: 83-103.

2 Adinoff AD, Hollister JR. Steroid-induced fractures and bone loss in patients with asthma. N Engl f Med 1983; 309, $265-8$

3 Geddes DM. Inhaled steroids: benefits and risks. Thorax 1992; 47: 404-7.

4 Haahtela T, Jarvinen M, Kava T, et al. Comparison of a beta- 2 agonist, terbutaline, with an inhaled corticosteroid budesonide, in newly detected asthma. N Engl f Med 1991; 325: 388-92.

5 Reed CE. Aerosol steroids as primary treatment of mild asthma. N Engl f Med 1991, 325: 425-6.

6 Lorentzson S, Boe J, Eriksson G, Persson G. Use of inhaled corticosteroids in patients with mild asthma. Thorax 1990 45: $733-5$.

7 Keeley D. Large volume spacers in asthma. BMF 1992; 305: 598-9.

8 Newman S, Millar A, Lennard-Jones T, Moren F, Clarke S. Improvement of pressurised aerosol deposition with Nebuhaler spacer device. Thorax 1984; 39: 935-41.

\begin{tabular}{|l|}
\hline Summary points \\
\hline Large volume spacer devices \\
- significantly reduce systemic steroid exposure \\
- significantly increase the amount of drug \\
deposited in the lungs
\end{tabular}

reduction in bone resorption with steroids, it seems likely that a reduction in bone formation will result in a reduction in bone mass. Urinary crosslinkers of collagen can now be measured and are a much better marker of bone resorption then hydroxyproline. These should be measured in future studies to evaluate the effect of steroids on bone resorption.

We believe that osteocalcin is the best marker of steroid exposure. Osteocalcin concentrations should thus be measured in further volunteer studies to compare the systemic absorption of newer inhaled steroids as well as steroids given by different methods such as diskhalers, rotacaps, and with the different designs of metered dose inhalers with the various spacers available. Inhaled steroids with higher firstpass metabolism should have a smaller systemic effect if inadvertently swallowed. Other tests of steroid exposure have not been sensitive enough to detect such small differences.

Spacers are bulky and patients dislike carrying them. We have shown that spacers significantly reduce systemic steroid exposure and they should therefore be advocated with all inhalers. Spacers are likely to reduce systemic effects by reducing the amount swallowed. A radiotracer study showed that a large volume spacer deposited $21 \%$ of the dose in the lungs and $16 \%$ in the oropharynx while $56 \%$ remained in the spacer. ${ }^{8} \mathrm{~A}$ metered dose inhaler alone deposited $10-15 \%$ of the dose in the lungs and $80 \%$ in the oropharynx..$^{8,22}$ Clinical studies using inhaled beta- 2 agonists have shown that spacers increase the effectiveness of bronchodilatation by metered dose inhalers. ${ }^{23,24}$

Spacers should be more widely prescribed with inhaled steroids. Further prospective studies are indicated to evaluate whether spacers protect bone mass.

This work was supported by a grant from The Fellowship of Postgraduate Medicine.

9 Brown JP, Delmas PD, Malaval L, Edouard C, Chapuy MC, Meunier PJ. Serum bone Gla protein: a specific marker for Moune formation in postmenopausal osteoporosis. Lancet 1984; i: $1091-3$.

10 Price PA, Osteocalcin. In: Peck WA, ed. Bone and mineral research, Ann 1, Amsterdam: Excerpta Medica, 1983; pp 153-99.

1 Meeran K, Hattersley A, Burrin J, Shiner R, Ibbertson HK. Oral and inhaled corticosteroids reduce bone formation as shown by plasma osteocalcin levels. Am $\mathfrak{f}$ Resp Crit Care Med 1994; in press.

12 Teelucksingh S, Padfield PL, Tibi L, Gough KJ, Holt PR. Inhaled corticosteroids, bone formation and osteocalcin. Lancet 1991; 338: 60-1.

13 Nielsen HK, Thomsen K, Eriksen EF, Charles P, Storm T Mosekilde L. The effect of high dose glucocorticoid administration on serum bone gammacarboxyglutamic acid containing protein, serum alkaline phosphatase and vitamin $\mathrm{D}$ metabolites in normal subjects. Bone Miner 1988; 105-13. 
14 Morrison D, Ali NJ, Routledge PA, Capewell S. Bone turnover during short course prednisolone treatment in turnover during short course prednisolone treatment in patients with chro

15. Hill CS, Wolfert RL. The preparation of monoclona antibodies which react preferentially with human bone specific alkaline phosphatase and not liver alkaline phosphatase. Clin Chim Acta, 1989; 186: 315-20.

16 Sharp AM, Handelsman DJ, Ristuccia RM, Turtle JR. Dexamethasone suppression of adrenocortical function. Clin Chem 1982; 28: 1333-4.

17 Farrer M, Francis AJ, Pearce SJ. Morning serum cortisol concentrations after $2 \mathrm{mg}$ inhaled beclomethasone dipropionate in normal subjects: effects of a $750 \mathrm{ml}$ spacing device. Thorax 1990; 45: 740-2.

18 Ginsburg L, Ludman PF, Anderson JV, Burrin JM, Joplin GF. Does stressful venepuncture explain increased midnight serum cortisol concentration? Lancet 1988; ii: 1257.

19 Meeran K, Hattersley A, Mould G, Bloom SR. Venepunc ture causes a rapid rise in plasma ACTH. Br $\mathcal{F}$ Clin Pract 1993; 47: 246-7.
20 Teelucksingh S, Padfield PL, Dicker I, Holt PR. A doubleblind placebo-controlled crossover study of effects upon the hypothalamic-pituitary-adrenal axis of beclomethasone diproprionate metered dose inhaler at $100 \mathrm{mcg}, 200 \mathrm{mcg}$ $350 \mathrm{mcg}$ and $500 \mathrm{mcg}$ four times daily in healthy adults. $A \mathrm{~m}$ Rev Respir Dis 1991; 143: A626.

21 Posen S, Cornish C, Kleerekorper M. Alkaline phosphatase and metabolic bone disorders. In: Avioli LV, ed. Metabolic bone disease New York: Academic Press, 1977; pp 141-81.

22 Newman S, Pavia D. Garland N, Clarke SW. Effects of various inhalation modes on the deposition of radioactive pressurised aerosols. Eur $\mathcal{F}$ Respir Dis 1982; 63 (Suppl 119): 57-65.

23 Tobin M, Jenouri G, Danta I, Kim C, Watson H, Sakner M. Response to bronchodilator drug administration by a new reservoir aerosol delivery system and a review of other auxillary delivery systems. Am Rev Respir Dis 1982; 126: 670-5.

24 Cushley M, Lewis R, Tattersfield A. Comparison of three techniques of inhalation on the airway response to terbutaline. Thorax 1983; 38: 908-13. 